\title{
Compensating for impoverishing injustices of the distant past
}

\begin{abstract}
Calls for compensation are heard in many countries all over the world. Spokespersons on behalf of formerly oppressed and dominated groups call for compensation for the deeply traumatic injustices their members have suffered in the past. Sometimes these injustices were suffered decades ago by members already deceased. How valid are such claims to compensation and should they be honoured as a matter of justice?
\end{abstract}

The focus of this essay is on these issues of compensatory justice. I want to look at the issue from the perspective of the eradication of systematic poverty affecting particular groups - where injustices of the distant past can reliably be identified as one of the major contributory factors to people's current poverty. This perspective brings realism to the discussion. To eradicate poverty requires more resources than most societies have easily available, therefore the discussion must take limited resources for the purpose of compensatory justice into account. The harmful characteristics and consequences of poverty adds a sense of urgency to dealing with issues of compensatory justice as well.

In the rest of the essay I will examine the following issues: [1] What kind of injustices qualify to be remedied by means of compensatory justice? [2] Should there be a limit to how far back in history one should go to compensate for injustice? [3] How can an injustice from the distant past be reliably identified as a cause of current problems? [4] Who should be compensated? [5] Who is responsible for compensation? [6] What form should compensation take? [7] Is the concept of compensatory justice backward looking or forward looking? I will argue for a moral obligation to the effect that serious injustices, perpetrated long ago against a group of people that caused poverty amongst them, ought to be compensated by society in a variety of ways to the original victims (if still alive) and their descendants.

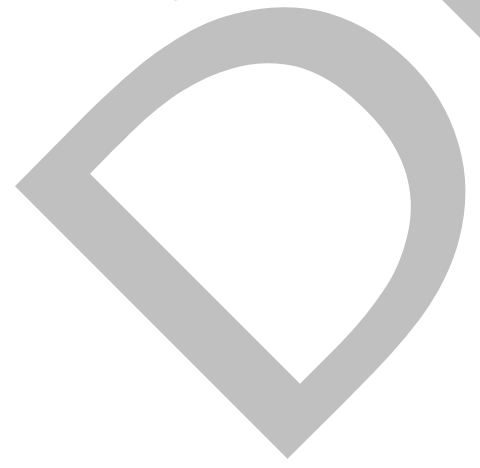




\section{Compensating for impoverishing injustices of the distant past}

Legal systems in democratic societies embody strong moral values that specify that no injustice ought to be done to a fellow citizen. If someone commits a clearly identifiable injustice to a fellow citizen, the injustice must be stopped and the offender reprimanded or punished. In such cases an injustice means an objective wrong, usually defined as a violation of a person's rights that results in injury, harm, loss, or damage. Stopping or punishing an injustice is, however, not enough. If serious harm or injury has been done to the victim of injustice or damage done to someone's property, the wronged person must be compensated. ${ }^{1}$ Compensation means that the victim's original situation must be restored (see Barnett 1991: 313, Sunstein 1991: 281 - 282, Wade 1978: 457).

Compensation can take different forms, although they express the same underlying principle. The principle is that the person who commits an injustice to another incurs a special moral relationship to the victim of the wrongdoing, i.e., a relationship of owing the victim, of being indebted to the victim for the injury, harm, loss, or damage caused (Fullinwider 1975: 310). The fundamental idea of compensation is to restore the balance of justice between victim and perpetrator of injustice, to somehow make good the victim's loss. Compensation is partially aimed at restoring the victim's former position or state, and thus tries to undo the wrong in such a way that the victim would be in a position similar to what the person would have been had the injury not occurred (Paul 1997: 102).

There is more to compensation, however. Compensation also aims to restore the balance of equality between victim and perpetrator of injustice. Compensation implies acknowledging and honouring the rights of the victims that have been violated by a perpetrator. The perpetrator has illegitimately assumed and exercised power over the victim through committing the injustice. ${ }^{2}$ Compensation thus symbolically restores the equality between victim and perpetrator as citizens of equal dignity and worth [see Paul 1991: 102 and Wilson 1983: 523]. ${ }^{3}$

Compensation can full or partial. Full compensation requires [1] attempts at repairing damage or harm as well as [2] restoring the moral status of victims as citizens with rights and dignity. ${ }^{4}$ Partial compensation occurs when only one of these elements is involved. Compensation can often be partial in another sense, i.e., not fully rectifying the wrongs committed. Reasons are the difficulties involved in some cases of either determining what would be appropriate to offer as compensation, or the enormity of the injury, harm, loss, or damage suffered that cannot in any way be fully compensated.

These ideas about compensation are firmly entrenched in legal practice in democratic societies and regulate relationships between individual citizens, relationships between representatives of the state and individual citizens, and relationships between individual citizens and organisations or companies.

However, attempts to apply these moral values about compensation to relations between groups of citizens [or between citizens of different countries] with a shared, but problematic and contested history, are very difficult. ${ }^{5}$ Why? There are several reasons. Note the following troubling questions that need to be resolved in order to make a convincing case for this kind of compensation.

[1] What kind of injustice is at stake? Many kinds of injustices happen and nothing is ever done about them. How serious must an injustice be and why must this particular one be compensated and others not? How far back in history must one go? ${ }^{6}$ How should such injustices be reliably identified? 
[2] If it can be established that there are injustices that occurred in the past that deserve to be compensated, who should be compensated? If the original victims of these injustices have already died, should their children or their grandchildren be compensated $?^{7}$ Are there grounds on which a person can be said to inherit the right to compensation from their ancestors? Is compensation due only to individuals who personally suffered an injustice, or should members of a group who suffered the injustice be compensated, as the group persists through time?

[3] Similar issues are encountered when one asks who should be held responsible for the injustice and who should thus compensate the victims of an injustice. Are the individuals who perpetrated the original injustice the only ones who should compensate the victims? Should their descendants in any way accept responsibility for these wrongs? Maybe the responsibility for some injustices is a collective one, that must be borne by a group, an organization, or by society rather than by individuals. When should we judge that an injustice was perpetrated by a society or a group, rather than just being a series of smaller injustices committed by a loose collection of unrelated individuals?

[4] If compensation is due in some cases, what kind of compensation should be given and for what purpose? Affirmative action is often used as a method of compensation. This practice grants victims of discrimination and oppression preferential treatment when applying for jobs. The purpose is to give victims of injustice a chance to get a job they were earlier denied for unacceptable reasons, despite their qualifications not being the best amongst the pool of applicants for that job. Another purpose is to increase the representation of a formerly discriminated against group in the workplace and to provide role models for young people to aspire to. But are these kinds of compensation and the reasons provided in support the best ways of dealing with this issue?

Calls for compensation are heard in many countries all over the world. Spokespersons on behalf of formerly oppressed and dominated groups call for compensation for the deeply traumatic injustices their members have suffered in the past. Sometimes these injustices were suffered decades ago by members already deceased. How valid are such claims to compensation and should they be honoured as a matter of justice?

The focus of this essay is on these issues of compensatory justice. I want to look at the issue from the perspective of the eradication of systematic poverty affecting particular groups - where injustices of the distant past can reliably be identified as one of the major contributory factors to people's current poverty. This perspective brings realism to the discussion. To eradicate poverty requires more resources than most societies have easily available, therefore the discussion must take limited resources for the purpose of compensatory justice into account. The harmful characteristics and consequences of poverty adds a sense of urgency to dealing with issues of compensatory justice as well.

In the rest of the essay I will examine the following issues: [1] What kind of injustices qualify to be remedied by means of compensatory justice? [2] Should there be a limit to how far back in history one should go to compensate for injustice? [3] How can an injustice from the distant past be reliably identified as a cause of current problems? [4] Who should be compensated? [5] Who is responsible for compensation? [6] What form should compensation take? [7] Is the concept of compensatory justice backward looking or forward looking? I will argue for a moral obligation to the effect that serious injustices, perpetrated long ago against a group of people that caused poverty amongst them, ought to be compensated by society in a variety of ways to the original victims (if still alive) and their descendants. 
What kind of injustices qualify to be remedied by means of compensatory justice? I want to defend the claim that a compensable injustice is a gross violation of the most important human rights, such as rights to life, to bodily and psychological integrity, to be free from all forms of violence, and to own property. ${ }^{8}$ Why use violations of human rights as indicators of compensable injustices? The vocabulary of human rights offer an already shared way of defining matters impartially that liberal democrats regard as high priorities that deserve governmental protection. If denied, the violation of these priorities leads to the various forms of serious harm that human rights are generally designed to avoid.

A group usually experiences such gross violations of human rights as deeply traumatic. Why this claim? Deeply traumatic injustices cause deep wounds to the bodies and minds of members of a group, or to the fabric of their social bonds. ${ }^{9}$ Such injustices cause severe harm to individuals, from physical injury and deep psychological trauma to loss of life. Injustices of this magnitude have traumatic effects and disabling consequences on primary victims that are often transferred to succeeding generations, making them secondary victims. It is intuitively plausible that people responsible for such events with disastrous consequences for the lives of victims should be held responsible for compensating victims. In Nozick's terms, if past injustices have shaped present holdings and determined current lives, whatever property has been unjustly acquired or fundamental human rights have been violated, must be rectified. ${ }^{10}$

Major injustices with strong negative consequences and devastating effects on victims may consist of largescale events such as a war of conquest, or they may consist of a cluster of smaller events equivalent to a major injustice, such as domination and oppression of a group based on irrational prejudice. ${ }^{11}$ Some major injustices consist of a combination of both large-scale and smaller events.

A major injustice that qualifies as a compensable injustice is usually one that a group remembers with feelings of moral outrage and resentment. ${ }^{12}$ Such remembrances usually form part of living memory. The injustice in dispute raises issues and generates debates that excite emotions that refuse to die or sink into oblivion. When told to descendants of victims, the experiences associated with the injustice come alive again and excite protesting emotions. Why is remembrance important? These memories and their associated emotions provide the spark for mobilisation by the victims, or others on their behalf, to demand that debilitating injustices be acknowledged, and rectified, however long the road to the eventual resolution of these issues might be. These memories give a rough indication of how serious and how deep the group judged the harms to be that they have suffered.

I want to argue that the current effects of past injustice, or lack thereof, make a difference to our judgement whether full compensatory justice is called for. The kind and scope of the compensation called for are partially determined by the debilitating effects still reverberating through the members of the affected group. Noticeable negative effects persisting as a result of the injustice strengthen the case for full compensation for compensable injustice.

The way the effects have been dealt with by victims can influence the kind of compensation owed to them, whether it be full or partial compensation. Partial compensation is appropriate in the following cases. If the effects have been countered and reversed and the trauma has by and large healed, compensation to deal with trauma is no longer called for, though compensation for the suffering endured might still be needed. If human agency has been restored, if skills and levels of competence have been developed to levels similar to those of other groups and if moral responsibility can be fully employed again, then compensation to restore 
these things is no longer needed, but compensation for expenses and efforts in restoration might be relevant. ${ }^{13}$ If the victims have recovered in these ways by themselves, it is to their benefit and psychological health: they have strongly proven and affirmed their independence and self-reliance. They can take pride in their ability to rise above their circumstances through healing themselves and reconstructing their skills to make a meaningful and worthwhile life. However, compensation acknowledging the harm, damage, or loss caused by injustice, recognising the efforts of victims to heal themselves, and awarding money for costs incurred should still be on the agenda. So too should be compensation that restores the moral worth and human dignity of victims.

One could argue that full compensation would be required in cases where negative effects persist through generations and where those effects are traceable to the original injustice. Their traceability usually results from the fact that the injustice has been reinforced or maintained in the intervening years. The reinforcement and maintenance of injustice in subsequent years often have the result that the original sufferers of that injustice and their descendants have no reasonable chance to get rid of the negative effects and consequences. Increased opportunities were not available for empowerment through generally available mechanisms of redress, or through improved access to societal resources. Sufferers of injustice could thus not create decent lives for themselves on a par with what is available to, and enjoyed by, other citizens. ${ }^{14}$

In cases of justified full compensation, the situation of victims [group members] and their descendants in the time between the original event and its current effects did not change substantially or sufficiently. Sufficient change would mean that they could have acted autonomously and independently to empower themselves to rid their lives of the negative effects and consequences of the injustice. This means that some kind of injustice, oppression, or prejudice kept the injustice or its consequences firmly in place or made it impossible to acquire resources, education, or opportunities to nullify the effects. It may also be that the persisting effects result from the harm done to their person, agency, or community, or from their social structure that was so devastated as to make recovery very difficult. If they consciously and deliberately made choices not to use meaningful opportunities to improve their lives, that would diminish the strength of their claims to full compensation.

Should there be a limit to how far back in history one should go to compensate for injustice? The answer depends largely on what has already been said. I will argue that one should go as far back in history as [1] there are major injustices that have effects persisting to the present and [2] there are clearly defined and describable victims of those injustices.

If one goes back more than a decade or two, the question arises when dealing with a compensable injustice becomes the responsibility of the victims alone. I want to argue that a stage may be reached when effects of compensable injustices on victims become the responsibility of the victims themselves and their descendants - a time when they ought to become agents of their own healing and recovery. Why this point of view? The argument hinges on the intuitively plausible ideas that [1] human beings can be or become agents of their own healing and recovery, [2] being such an agent depends on resources available before and after the traumatic event, and [3] even deep harm does not totally extinguish human resilience in the face of adversity.

To determine the stage when effects of compensable injustices become the responsibility of victims themselves requires a complex judgement. In this judgement we must take into account the scope and 
consequences of the trauma caused by the injustice, the physical, mental, and social resources available to the victims before the event, and the extent of the damage to these resources. One must determine which aspects of their resources survive after the traumatic injustice to enable the victims to deal with the trauma. The levels of prejudice, discrimination, and oppression must be noted that remain in place after the injustice, or newly develop in the wake of the injustice, that contribute to diminish the victims' opportunities for recovery and their access to support to deal adequately with their situation.

\section{III}

An important issue of compensatory justice is how a compensable injustice from the distant past can reliably be identified as a major contributory factor to people's current misery or poverty. I want to argue that such a reliable identification can be made. It is possible to establish how one event, or a series of events, can have effects on, or consequences for individuals, communities, groups, or societies. These effects and consequences, if left untended or if reinforced by human action, persist as events creating further effects and consequences. These new effects and consequences can be similar to their predecessors, or be new distortions and perversions that affect the lives of the primary victims. These effects can be so drastic that secondary victims are created from people in close association with primary victims. The latter often cannot avoid transferring effects and consequences to others. ${ }^{15}$

How can a compensable injustice from the distant past be reliably identified? First, one must determine the current level of poverty of victims through standard measurements and indices of levels of poverty developed in the social sciences. Next, we need to identify that a particular group of poor people has been poor for quite some time. Their poverty is often not as recent as 5 or 10 years ago, but more often than not goes back a generation or two. The history of individuals, families, and communities can easily be traced this information is often public knowledge - to verify claims of conditions of poverty transferred from one generation to the next. The inability of individuals, families, and communities to escape traps of poverty that result from major injustices and other factors reinforcing the consequences of injustices, is an important indicator of the need for full compensation.

A next move would be to investigate the major injustice from the distant past that is allegedly responsible for causing poverty that have been plaguing a group of people for more than a generation. This injustice must have been a major event with serious consequences and strong effects on the group. It must have seriously wounded their agency and diminished their means to develop. The injustice must furthermore have left psychological wounds that seriously affected their self-confidence, self-reliance and self-image, to such an extent that these psychological wounds detrimentally affected succeeding generations.

We must thus establish the harm done to the agency and autonomy of victims, their self-reliance and their capabilities for effective functioning, and the reduction in their level of well-being. A trustworthy case must be presented that shows convincingly that such harms resulted from the consequences and effects of major injustices. Major injustices typically have effects and consequences such as loss of life, serious bodily injuries, deep emotional scars, damage to property or loss thereof, destruction of interpersonal or communal relationships, and loss of opportunities for personal and communal development and growth. These are all deeply traumatic events and their effects on the primary victims and their offspring must be established through independent investigation. Not only must we determine that these things have happened, but also how deep the harm was, how comprehensive the damage, and to what extent the trauma affected their personal and collective agency and their abilities to make a good life for themselves as individuals and as 
community. How these disabling effects were carried over to the next generations must also be reliably established.

Typical examples of injustices with major, deeply traumatic consequences and effects are the following. Conquest in an unjust war, as in colonialism, is an example of a major single event, or a series of bigger events. Political domination and oppression are examples of a mixture of smaller and larger events, as could be seen in a comprehensive series of injustices over many decades directed at black people through apartheid in South Africa. Women's oppression is another example of a series of injustices of different ranges, with the cumulative effect of oppressing and dominating women into disempowered human beings, deprived of equal developmental and growth opportunities.

While sufficient evidence of the broad outlines of compensable injustices is available, detailed evidence or abundant first person accounts might not exist. This need not be a problem. The nature of these compensable injustices as deeply traumatic events is so well-known that any person can form an idea of what it means to lose a loved one in war, to have your house burned down or flattened by a bulldozer, to be tortured whilst in detention without trial, to be raped by strangers, or to be continuously humiliated by your partner in a love relationship.

Slightly more detailed examples of how philosophers depict two major events as injustices with continuing effects might be illuminating. Onora O'Neill's [1987: 80] describes the enslavement, invasions, and dispossession of indigenous peoples during European colonialism as consisting of serious harms and injuries resulting from gross violations of human rights that would today be judged as crimes against humanity. The effects of these human rights abuses are still "all around us" and those effects are "immeasurable, complex, and intricate" [O'Neill 1987: 80]. ${ }^{16}$

Thomas Nagel [1973: 381] depicts the effects of racial discrimination in the USA as creating a group whose social position is "exceptionally depressed, with destructive consequences both for the self-esteem of members of the group and for the health and cohesion of the society." Bernard Boxill [1978] elaborates on this injustice by characterising racial discrimination as in part "judgemental injustice." This consists in letting black people know they deserve less consideration and respect than white people do. An arbitrary characteristic, their skin colour, is the reason why they are denied opportunities, excluded from participation in societal activities, treated with disrespect, and judged to be inferior. Judgemental injustice also condemns them to the uncertainty of not knowing when they will suffer abuse for being black. As a result of these attitudes and actions against them, they lose self-confidence and self-respect.

We now have access to the two outer limits of the investigation into compensable injustices: the original deeply traumatic injustice and the current poverty. Perhaps the more difficult part is to convincingly show that the original injustice is a causal factor in the genesis of current poverty. I want to present an argument in support of the possibility that such a case can be made.

For poor people to make a convincing case for full compensation of a major injustice of the distant past, we must first examine the already gathered evidence of the impact of the major, deeply traumatic injustice on the group immediately after its occurrence. On the one hand we must note what coping skills, mechanisms, and resources the victims had available and how these were affected by the trauma. Next we must investigate forms of oppression, discrimination, and prejudice that continued afterwards that made their recovery and healing difficult, if not impossible. We must examine how oppression, discrimination, and prejudice manifested in laws, attitudes, overt and cover behaviour, policies, priorities in budgets, etc. To 
demonstrate such a link between a major injustice and current poverty, information about the following factors must be presented: [1] seriously affected coping skills, mechanisms, and resources, [2] continuing injustices denying them space for mobilisation of human and other resources for recovery, or [3] cramped political space forcing them into stunted political growth and resulting in severely curtailed influence on society. ${ }^{17}$ Thus, they must demonstrate an inability for healing and recovery, as well as for mobilisation to achieve self-renewal.

To establish the case for compensation convincingly, a group must thus be able to point to obstructions that impeded their recovery in the years between the initial impact of a major, deeply traumatic injustice and their current state of poverty.$^{18}$ Obstructions would mainly result from the denial of political rights which is profoundly disabling, continued oppression and discrimination which close opportunities and shut off chances of being heard, and a lack of human and economic resources which stifles attempts to engineer one's own recovery. A group must also show that such obstructions constrained their attempts to provide children a better future in which such obstructions would have no adverse effects on the development and growth of the children to mature self-realization. ${ }^{19}$

If such obstructions can be shown to be present to a degree significant enough to make any form of recovery difficult, a strong presumption exists in favour of acknowledging [1] that both primary and secondary victims have a strong case for compensation and [2] that not only the first generation of perpetrators of injustice are guilty and thus responsible for the plight of the poor. Obstruction that impeded recovery from a major injustice suggests that the descendants of the original perpetrators of the major injustice have committed obstructing injustices. Through these injustices they have become complicit in the plight of the victims, in the sense that they have become participants in a continuing process of committing injustices against the victims. They are thus co-responsible for the plight of the descendants of the original victims.

\section{IV}

Who should be compensated? Individuals or groups? Only the original sufferers of the injustice or their descendants as well? Only their direct descendants? Whom should be compensated when most of the original sufferers from injustice have already died? Is there a cut-off point for how far the rippling effects of a traumatic injustice can reach through the complex histories of families, communities, and friendships? What are the links between continuing rippling effects and the strength of human agency capable of arresting and eradicating those effects?

Compensation for major injustices of the distant past - those responsible for contemporary poverty - is almost exclusively a group thing and not an individual matter. ${ }^{20}$ The major injustices that qualify as compensable injustices, regardless of the fact that they occurred long ago, carry a distinct social or group aspect. $^{21}$ Two examples will suffice to explain this social or group dimension. Major injustices, like wars of conquest, were fought in the name of, and for the benefit of a country, or a particular group or community of distinct people. The soldiers fighting the war did so in their capacity as representatives of a government or a group, acting on commands of such principals. They fought against a community owning valuable land or a society in control of valuable resources.

Even major injustices, like racism or sexism, that consist of series of smaller events perpetrated by individuals and groups against other individuals and groups manifest an inescapable group dimension. Racism and sexism were perpetrated against identifiable groups of individuals, marked by specific visible 
characteristics they had no control over. The perpetrators of racism and sexism practiced their prejudice from within constructed identities based on specific, preferred social or group characteristics.

In both examples above the targets or objects of the injustices were not individuals in their personal capacity, but individuals as representative of their group, marked by their characteristic identifications. ${ }^{22}$ Compensable injustices were committed against groups and we have already established that the results and consequences of these injustices can be transferred from the directly affected generation to the next one who did not themselves experience the injustice. A major injustice - or cluster of ongoing injustices - can have serious and debilitating effects on the primary victims. Through injuries and harms to body and mind, damage to possessions and property, loss of life, liberties, and functions, and ruptures of the social fabric of communities, primary victims may lose any one of a series of capacities that contribute to making a worthwhile life. ${ }^{23}$ These effects of a major injustice can be perpetuated and transferred from one generation to the next if sufficient space and resources for recovery are not available. Thus, all those adversely affected by a compensable injustice - even those more than one generation removed from the original injustice must be compensated in some or other way.

If members of a group must be partially or fully compensated, what should the aim be? The aim of compensation must surely be one or more of the following: to repair their capacities to make a good life; to give them something equivalent in return for their injuries and losses; to restore relationships and resources; to acknowledge symbolically the serious violations of their rights and restore their dignity as equal citizens, whether it be through apologies or memorials. ${ }^{24}$ Compensation must empower people disadvantaged by injustices of the past to take up their place as citizens of equal worth and dignity with at least a minimum decent lifestyle. Victims of injustice must have their agency restored, so that they can take proper care of themselves within a community of interdependent free and equal agents. Compensation ought to be due to [1] the original sufferers and [2] their descendants who have suffered as a result of the injustices done to their ancestors, and still have to deal with the after-effects of the original injustice.

Although the injustices concerned affect groups in particular, that does not imply that all members were affected equally. The effects and consequences of an injustice do not strike everyone similarly and some people escape most of them or overcome them more easily than others can. A lot depends on how a person can dodge or overcome the way that injustices from the distant past have been reinforced or maintained. Can the exact extent of the harm, injury, loss, or damage of each individual thus be determined so that each individual's exact amount of compensation can be calculated? No, for two reasons. One reason is that it would be virtually impossible, highly controversial, and also too costly to make such fine-grained, specific investigations and detailed judgements about degrees of individual loss, harm, and damage. ${ }^{25}$ Another reason for being unable to determine exact amounts of compensation is that although some individuals might have been less directly affected by injustice than others, this does not adequately reflect the harm and suffering they may have experienced indirectly. ${ }^{26}$ They were often also strongly negatively influenced by sharing the traumas that friends, family, and colleagues have experienced, or they may have been affected by living in an atmosphere where their kind were despised and emotionally or physically abused. They lived with the awareness that the possibility of becoming a victim of trauma or abuse was always alive. Furthermore, ideological abuse, where a system of ideas with its accompanying justification reinforce injustices by deprecating and degrading victims, often legitimates physical and emotional abuse and contributes to low self-esteem. 
Who is responsible? Individuals, groups, or the state? Can the descendants of the people who originally committed the wrongs be held responsible for the injustices of their ancestors? If so, under what conditions? Can compensation only be provided by the perpetrators of injustice, or can someone else provide compensation vicariously $?^{27}$

I want to argue that the state must take primary responsibility for compensable injustices. ${ }^{28}$ The reason is that the state has failed to treat all its members fairly and equitably, albeit in a previous era and in a different manifestation. ${ }^{29}$ That the state treated some members unfairly and unjustly is clear [1] from injustices perpetrated by governments, [2] from group behaviour sanctioned by a government or [3] from acts knowingly allowed by a government willingly watching how a particular group of citizens were unjustly and unequally treated and dominated into a desperate social position of vulnerable subordination. For this reason a government representing the state was responsible for the inequitable and unfair treatment of a group of its citizens in the past. ${ }^{30}$ Therefore the current government as representative of the state must take over the responsibility to rectify this wrong, albeit that the injustice was committed by a former representative of the state. Thus, the government - and indeed society as a whole - must accept responsibility for the plight of the victims and the need for compensation. ${ }^{31}$

Yet, even individuals can and should be held responsible, if they are or have become complicit in committing the injustice or through their everyday behaviour maintained and reinforced the negative consequences of a major injustice. How could they have become complicit? They became complicit through acts of commission, by adopting or acquiring prejudice, or through acts of omission, by ignoring the plight of the vulnerable sufferers from injustice. Through these acts of omission or acts of commission individuals may have become accessories in maintaining the original injustice or its negative effects and consequences, instead of becoming aware of the immorality of the injustice being done to the victims, protesting it, trying to stop it, and undoing its effects. This view assumes the commonsense notion that as human beings and fellow citizens we expect a certain level of moral agency from one another: we ought to have the moral capacity to judge certain practices, states of affairs, or acts as unjust or unfair and act on those judgements. To act on such judgements might require us to condemn and remove injustices and their consequences, or do so when made aware of them by fellow citizens, especially the victims of injustice. If not, we stand guilty before our fellow citizens and have to give an account why we have failed to respond, why we refused to see their plight as expressed on their faces, why we chose not to hear their cries of suffering, or why we have violated or ignored the implications of the values of our shared humanity.

There is another way in which individuals can be held responsible for compensable injustice, although to a lesser degree. They are responsible even if they had no part in committing the original injustice or if they did not participate in any activities reinforcing or maintaining current injustices or the effects thereof, but they have nevertheless willingly and knowingly enjoyed the benefits resulting from the injustice and its consequences. How can this claim be supported? Compensable injustices are often committed to strip a group of financial, property, social, and other resources or to limit their access to these resources so as to transfer the resources to the dominant group. So-called innocent members of the dominant group mostly willingly accept their better-off position whilst being aware - or being made aware by victims or others on their behalf - of the worse-off position of members of the disadvantaged group. Many such beneficiaries may presume their societal arrangements to be natural and fixed, but in most unjust societies sufficient voices of protest and cries of suffering are available to appeal to their conscience. ${ }^{32}$ As beneficiaries of injustice, they are thus aware of their privilege and are morally confronted by the victims of injustice to 
reject and remove the negative disempowering and disabling consequences of injustice for victims. Not responding to victims and exploiting their own privileged position make the beneficiaries at least partially responsible for the continuing presence and consequences of a major injustice, though they are not responsible for the original injustice. ${ }^{33}$

I am arguing for degrees of responsibility. The original perpetrators of injustice have full responsibility for committing the injustice. Their descendants might have lesser responsibilities for their roles in either perpetuating the effects and consequences of the injustices or by refusing to listen to the cries of suffering and voices of protest directed at them. The government as representative of state and society incurs a longterm responsibility to take care of the well-being of its citizens and thus to restore their position once the government has either allowed or committed injustice against a specific group of members. ${ }^{34}$

\section{VI}

What form should such compensation take? Many forms of compensation are possible: their aim should be to restore victims of compensable injustice to full citizenship as persons [1] with dignity and worth and [2] who can function as interdependent agents who take full responsibility as equals in society.

The different forms of compensation depend on the kind of loss, injury, harm, or damage done to victims of injustice. What is clear, though, is that compensation imposes a twofold obligation on the former perpetrators and reinforcers of injustice. The first is to restore, rectify, or compensate for the victims' loss, injury, harm, or damage (see Kershnar 1999: 84). In this case in kind compensation should take preference if land had been stolen, return the same land or something similar and acceptable. ${ }^{35}$ In cases of loss of life or trauma the harm cannot be undone, but some of the effects and consequences can be softened. For example, the loss of a breadwinner can be compensated by means of an income grant, financial assistance for health and education, provision of adequate shelter, and so on.

In many cases where the injustice cannot be undone and in cases of loss of land, a large part of what is at issue is the loss of the means to make a livelihood, to establish meaningful relationships within a community, the loss of caretakers and breadwinners who should have provided livelihoods, caring upbringing, and life chances, and the lack of role models who could have facilitated job training, social skills, and practical intelligence. For these reasons it would make sense to compensate people through special education and training programmes, or through special access to education, empowerment opportunities in business to develop their human agency, and access to life skills to make successful lives for themselves as full and equal citizens. ${ }^{36}$ The lives of primary and secondary victims might eventually turn out to be different from the ones they would have had without the injustice occurring, e.g. they might not be able to be farmers as their ancestors, or live as hunters in exactly the same area as their forebears. Such differences resulting from their compensation suggest that complete restoration might never be possible, despite full compensation. ${ }^{37}$

The second obligation compensation imposes on the perpetrators and reinforcers of injustice is to equalise the relationship between victim and perpetrator. The inequality in relationship results from the perpetrator assuming a relationship of power and dominance with destructive consequences for the victim without the latter's consent. What must be done to equalise the relationship between victim and perpetrator? The dignity and worth of the victim must be restored through an acknowledgement of the rights that have been violated. This can best be done by means of an apology or through enforcement of those rights by a court of law. To acknowledge guilt, to ask forgiveness, and to pursue reconciliation based on shared moral rejection of the 
injustice facilitate the equalisation of the relationship. Part of this restoration of the equal dignity of victims as citizens is to negotiate the nature of all aspects of compensation with them and to make decisions concerning the manner of compensation only through eliciting their consent.

Some forms of compensation might not succeed in replacing losses or repairing damage, because they are irreparable. In such cases, like the loss of loved ones, compensation must acknowledge the intensity of suffering, the loss of a valuable human resource, and symbolically restore victims to equal citizenship. Other forms of compensation might not be successful in restoring harms or injuries, because the injustices might have been devastatingly destructive. In such cases, like permanent disabilities, compensation must aim to ease unbearable pain, to make someone's nearly destroyed life somewhat easier, and to symbolically acknowledge the gravity of the injustice done. ${ }^{38}$

\section{VII}

Is the concept of compensatory justice backward looking or forward looking $?^{39}$ [see Boxill 1978: 249]. Are backward-looking justifications that aim to remedy harms done to people in the past better than forwardlooking justifications that aim to improve future life for everyone? What exactly are the differences between these two justifications?

I want to argue that a backward looking perspective is crucial. There must be some backward looking justification, spelling out in detail the injustice done and how it was maintained and reinforced through the intervening years. There must be a justification of how some people are still suffering today because of what was done to their ancestors and reasonable evidence must be presented to support these links between present poverty, misery and suffering on the one hand and past injustice on the other. In this sense a backward looking justification is an explanation of how the present came to be [see Amdur 1979: 238 and Paul 1991: 100].

Although looking backwards is crucial, this does not mean that the past is the main issue in demands for compensation of injustices of the distant past. These demands are not to change the past so much as it is a desperate cry to change the present. People judging themselves victims of injustices long ago experience themselves and their group as inferior or disadvantaged or unequal now, when they compare the average position and standing of their group members with the current average position and standing of other members of society. ${ }^{40}$ They judge themselves and their group in need of compensation to make up their accumulated losses, to improve their relative standing in society as measured by several indices, and to gain respect as equal functioning and contributing members of their diverse society.

A forward looking justification is important as well - anything done in the name of justice must raise the future well-being of society and improve the quality of cooperation within a community of citizens for the better. To establish and maintain justice in a society ought to secure the interests of every citizen. So compensation must not only improve the lives of a group of marginalized people, but enhance the quality of life available to all citizens in their country.

The backward and forward looking perspectives can be joined in a metaphor: compensation must clear up a festering wound in the body of society for the benefit of improved functioning of all component parts. Such a societal wound will have at least three parts: [1] a certain group suffers a decline in life chances and opportunities for personal betterment and this decline manifests in poverty, [2] discrimination based on group characteristics shows in humiliating and denigrating behaviour towards members of the group, in the 
silencing of their voices and concerns, and in the consequent prevention and inhibition of healing and recovery, and [3] the contents of propositions [1] and [2] are directly linked to a compensable injustice from the distant past.

A societal wound is not something that strikes a number of individuals randomly or naturally, but members of a dominant group inflict it on a vulnerable group for reasons such that the dominant group dislikes the subordinated group for some of their shared group characteristics, wants their resources, or exploits their labour and services. I thus want to argue that injustices of the distant past are actually issues of the present, ${ }^{41}$ showing that current inequalities, domination, and oppression have histories of being brought into existence and being nurtured by dominant groups. Through healing such wounds, society itself will grow into a better state of moral health in future and become more sensitive to the voices, issues, and plight of any new category of marginalized and vulnerable people that might arise.

At times it seems plausible that the contents and implications of this view of compensatory justice for aggrieved groups can be transposed into something like John Rawls's theory of justice without loss of content, but with gains in simplicity. ${ }^{42}$ The two foci of compensatory justice can be captured by the two Rawlsian principles that secure equal dignity, fair equality of opportunity, and improvements of the position of the least advantaged members of society as prerequisite for justified inequalities of income and wealth. This transposition seems to have the advantage of discarding the backward looking justification. ${ }^{43}$ Why not rather work on these Rawlsian principles that can secure similar results as the principles of compensation? Why not just forget about the ugly past, as so many of the perpetrators of injustice and their descendants fervently wish? Or is this advantage of ignoring the past a dubious one?

The main reason to stick to the principles and ideas of compensation is that such a transposition to Rawlsian principles would deprive victims of injustice of their personal and collective narratives that make sense of their experiences and the condition of their lives. ${ }^{44}$ These narratives also construct their history that gives them identity, and they offer them stories that give them hope for liberation with dignity from oppressive circumstances. Also, why should descendants of former elites be satisfied to be classified as poor or least advantaged with little state aid forthcoming to improve their position if through compensatory justice their descent from, and position as elites might be recognised and restored ${ }^{45}$

\section{VII}

There is a strong emotional reaction against compensatory justice by former perpetrators, reinforcers, and beneficiaries of compensable injustices. They either deny responsibility for past events or claim new injustices are being committed when a group is compensated for past injustice. Perhaps they will view the issue differently if they interpret compensatory justice as a special case of transformatory justice.

Transformatory justice deals with issues Rawls ${ }^{46}$ assigns to non-ideal theory or partial compliance theory. These issues deal with injustice in societies and how best to transform a society to reduce or eliminate injustice. The term transformatory justice implies that existing political institutions, policies, practices, ideas, and citizens of unjust societies must be changed, modified, reformed, and reshaped to embody and express the newly negotiated values of justice fundamental to a new constitution.

In the process of the transformation of an unjust society into a just one, the acceptance of a theory of justice as foundation for the new society is a milestone. From this point onwards, the accepted theory of justice functions as a Rawlsian ideal theory guiding further processes of transformation. Compensation for 
injustices of the distant past is merely one of those further processes of transformation and not so different from the others.

The way in which other aspects of transformation share many goals and characteristics with compensatory justice can be explained as follows. When assigning formerly disenfranchised and oppressed people rights to equal liberties as part of transforming an unjust society, a government is rectifying injustices that might have existed for decades or even centuries. Assigning these rights has enormous implications. In new institutions of governance, new interest groups demand and formulate new policies to change the present that was shaped and formed by many injustices from the past. Such policies could include setting up a truth commission to identify victims and perpetrators of serious human rights violations, implementing affirmative action to rectify patterns of racial prejudice in job appointments, changing priorities of governmental budgets to benefit those disadvantaged for many years by the neglect of unjust governments, and so on. Compensating for impoverishing injustices of the distant past is merely one part of a comprehensive set of policies to undo the injustice of the past.

Compensatory justice starts with the acknowledgement that all members of society are now regarded as citizens of equal dignity, but many were not treated as that in the past. A lot of current misery and suffering can be traced directly to acts of fellow citizens based on assumptions about the supposed inferiority of the victims. If governmental representatives of the new foundational theory of justice have the power to show they disagree with past injustices and they have the capacities and means to ameliorate the consequences and effects thereof, then to refrain from doing so is equal to condoning and perpetuating past injustice.

Compensatory justice is thus tied to an ideal theory of justice and its embodiment and expression in a transforming society on its way to justice.

\section{Bibliography}

1. Amdur, Robert. 1979. "Compensatory justice: The question of costs," Political Theory, Vol. 7, No.2, pp. $229-244$.

2. Anderson, Elizabeth. 1991. "Compensation within the limits of reliance alone," Nomos, Vol. 33, pp. $178-185$.

3. Barnett, Randy, E. 1991. "Compensation and rights in the liberal conception of justice," Nomos, 33, 311-354

4. Bayles, Michael D. 1972-1973. "Reparations to wronged groups." Analysis, Vol.33, pp.182 - 184.

5. Boxill, Bernard. 1978. "The morality of preferential hiring," Philosophy and Public Affairs, Vol. 7, No.3, pp.246- 268 .

6. Carens, Joseph H. "Compensatory justice and social institutions," Economics and Philosophy, Vol. $1,1985,39-67$

7. Dworkin, Ronald. Sovereign Virtue. Cambridge, Massachusetts: Harvard University Press.

8. Fishkin, James S. 1991. "Justice between generations: Compensation, identity and group membership," Nomos, Vol. 33, pp.85 - 96.

9. Fullinwider, Robert K. 1975. "Preferential hiring and compensation," Social theory and practice, pp. $307-320$.

10. Goldman, Alan H. 1975. "Limits to the justification of reverse discrimination," Social theory and practice, pp. $289-306$.

11. Goldman, Alan H. 1977. "Reply to Jaggar," Social Theory and Practice, Vol.4, No.2, pp. 235 237.

12. Goodin, Robert . 1991. "Compensation and redistribution," Nomos, Vol.33, pp.143-177. 
13. Heslep, Robert D. 1976. Educational theory, Vol. 26, 147-153.

14. Jaggar, Alison. 1977. "Relaxing the limits on preferential treatment," Social Theory and Practice, Vol.4, No.2, pp. 227 - 235.

15. Kavka, Gegory S. 1982. “An internal critique of Nozick's entitlement theory,” Pacific Philosophical Quarterly, 6, 371-380.

16. Kershnar, Stephen. 1999. "Uncertain damages to racial minorities and strong affirmative action," Public Affairs Quarterly, Vol. 13, No. 1, pp.83 - 98.

17. Nagel. Thomas. 1973. "Equal treatment and compensatory discrimination," Philosophy and Public Affairs, Vol. 2, pp.348-363.

18. Nickel, James W. 1974. "Classification by race in compensatory programs," Ethics, Vol. 84, pp.146- 150 .

19. Nozick, Robert. 1974. Anarchy, State, and Utopia. Oxford: Basil Blackwell.

20. O’Neill, Onora. 1987. "Rights to compensation," Social Philosophy and Policy, Vol. 5, No.1, pp.72-87.

21. Paul, Ellen Franken. 1991. "Set-asides, reparations, and compensatory justice," Nomos, Vol. 33, pp. $97-139$.

22. Rawls, John. 1971. A Theory of Justice. Oxford: Oxford University Press.

23. Shanley, Mary Lyndon \& Mary C. Segers. 1979. "On Amdur 'Compensatory justice: The question of costs,"” Political Theory, Vol. 7, No.2, pp. $414-416$.

24. Sher, George. 1976 - 1977. "Groups and justice," Ethics, Vol. 87, pp. $174-181$.

25. Sunstein, Cass. R. 1991. "The limits of compensatory justice," Nomos, Vol. 33, pp.281 - 310.

26. Taylor, Paul W. 1972-1973. "Reverse discrimination and compensatory justice," Analysis, Vol.33, pp. $177-182$.

27. Thompson, Janna. 2001. "Historical injustice and reparation: Justifying claims of descendants," Ethics, Vol.112, pp.114-135.

28. Wade, Francis C. 1978. "Preferential treatment of blacks," Social Theory and Practice, Vol.4, No.4,pp. $445-470$.

29. Waldron, Jeremy. 1992. "Superseding historic injustice," Ethics, Vol. 103, No. 1, pp. 4 - 28.

30. Walzer, Michael. Spheres of Justice. Oxford: Basil Blackwell, 1985.

31. Wilson, John. 1983. "The purposes of retribution," Philosophy, Vol. 58, No. 223, pp. 521 - 527.

32. Young, Iris Marion. 1990. Justice and the Politics of Difference, Princeton, New Jersey: Princeton University Press.

\footnotetext{
${ }^{1}$ Taylor (1972-1973: 179) talks about the obligation for "some form of compensation or reparation" that must be made to restore "the balance of justice when an injustice has been committed to a group of persons."

${ }^{2}$ Wilson (1983: 523) refers to the fact that a perpetrator of injustice does not only gain a particular advantage, but such a person "has adopted an unjust superior position" and "infringed the rights or status of his (her) fellows as equal negotiators and deal-makers."

${ }^{3}$ Wilson (1983: 523) spells out the significance of repentance and apology in the metaphoric language of material compensation. He says repentance and apology restore equality, as the "repentant person acknowledges the innocent's rights and the innocent thus gets his (her) own back."

${ }^{4}$ Amdur (1979: 241) articulates something of this aspect when he refers to the need that African-Americans should be compensated for the "humiliation inflicted by segregation." Waldron (1992: 7) suggests that "a symbolic gesture may be as important to people as any material compensation."

${ }^{5}$ Wilson (1983: 522) articulates both the simplicity and the complexity of this issue. The simplicity of the issue is the idea that "when another takes away what is rightfully and desirably mine, he ought to give it back." The complexity of compensation between groups is that it is "not always easy to see what sort of, or how much, compensation A should give to B if A cannot restore the original situation."

${ }^{6}$ Waldron (1992: 15) refers to widespread beliefs that deny compensation for injustices committed long ago. He refers to the belief that "after several generations have passed, certain wrongs are simply not worth correcting." A further belief he refers to is that some rights "are capable of 'fading' in their moral importance by virtue of the passage of time and by the sheer persistence of what was originally a wrongful infringement." However valid these beliefs might be, they do not affect my position which argues for compensation for major injustices with effects and consequences which persist through time, often as a result of being reinforced and maintained.

${ }^{7}$ Paul (1991: 103) thinks that "some rights violations lapse with time and, therefore, are uncompensable."

${ }^{8}$ See Barnett's claim (1991: 313) that we need objective criteria to "distinguish ... compensable from noncompensable injuries."

${ }^{9}$ O'Neill (1987: 80) refers to "gross violations of human rights" and injustices that would count as "crimes against humanity." Nagel (1978:

361) identifies a group to whom compensation is owed as one "whose social position is exceptionally depressed, with destructive consequences
} 
both for the self-esteem of members of the group and for the health and cohesion of the society." Ward (19XXX: 459) judges compensable injustices as inhuman situations where victims have been "depressed and degraded by years of injustice."

${ }^{10}$ See Robert Nozick's theory of justice as entitlement, especially the part of rectificatory justice (Nozick 1974: 150-153).

${ }^{11}$ Jaggar (1977) shows the links between these smaller injustices when she says that overt job discrimination "could hardly occur except in a social context where such discrimination was widely considered to be acceptable and where it could appear to be justified because of the existence of a universal covert discrimination."

${ }^{12}$ Waldron (1992: 5) points out that great injustice has a well-known characteristic, "that those who suffer it go to their deaths with the conviction that these things must not be forgotten."

${ }^{13}$ Note what Boxill (1978: 249) says on this point: "For if they have overcome their injuries, they have borne the costs of compensation that should be borne by those who inflicted the injuries." He adds as reason for the remaining claims of victims to some form of compensation that a person "who has worked hard and long to overcome an injury is not what he would have been had he never been injured."

${ }^{14}$ Waldron $(1992: 19,20)$ claims that often a "long-stolen resource" no longer plays a significant part in people's lives, because they "must have developed some structure of subsistence." This implies that their claim to compensation loses credibility. Somehow Waldron ignores the point that people's lives often have deteriorated significantly through many generations as a result of the irreplaceability of "long-stolen" resources. Besides being disabled by the original injustice, their recovery is more often than not impeded by subsequent maintenance and reinforcement of the original injustice. Waldron (1992: 27) acknowledges this possibility when he says it is a fact that "many of the descendants of those who were defrauded and expropriated live demoralized in lives of relative poverty - relative, that is, to the descendants of those who defrauded them."

${ }^{15}$ Waldron (1992: 8) makes an argument against compensation for historic injustices based on his problems with the subjunctive approach that uses counterfactual reasoning to approximate "what would have happened if some event (which did occur) had not taken place." This hypothetical reconstruction of possible events is then the basis to "change the present so that it looks more like the present that would have obtained in the absence of the injustice..." I will show that this approach is not the only one to establish a factual basis for compensation for historic injustices.

${ }^{16}$ See O'Neill's (1987) rejection of compensation, despite her vivid recognition of the harm done by past injustice.

${ }^{17}$ Sunstein's (1991: 297) reference to affirmative action as "an effort to overcome the social subordination of the relevant groups" reinforces this point.

${ }^{18}$ This importance of this point can be illuminated by Barnett's remark (1991: 318) that the liberal conception of the rule of law requires "that sufficient evidence of liability must exist and be presented before a remedy may be imposed."

${ }^{19}$ Janna Thompson [2001: 114-135] uses this line of argument to justify compensation.

${ }^{20}$ See Sher (1976-1977: 174 - 179) for a position that refuses to acknowledge any notion that groups are involved in issues of compensatory justice. For Wade (1978: 464) the matter in the case of African-Americans is clear: "since the injustice the blacks have lived with was directed towards the group, reparation must follow the same pattern."

${ }^{21}$ Taylor (1972-1973: 181) also describes the victims as group, because they "were the collective target of an institutionalized practice of unjust treatment." Perhaps he overstates his case when he says the group was "created by the original unjust practice." The group with their specific characteristics might have been drawn into the spotlight, have been focused on in a special way, or they might have been forced to react in ways that strengthened their group identification and mobilization.

${ }^{22}$ My view coincides with one proposed by Taylor (1972-1973: 148) when he says the following: "For the injustices done to a person are based on the fact that he has characteristic $\mathrm{C}$. His being $\mathrm{C}$ is, other things being equal, a sufficient condition for the permissibility of treating him in the given manner."

${ }_{23}$ See Boxill's (1978: 254 - 255) comment: "In order to retain their sanity and equilibrium in impossibly unjust situations, people may have to resort to patterns of behavior and consequently may develop habits or cultural traits which are debilitating and unproductive in a more humane environment." He calls these cultural traits "unjust injuries" and says they "may be deeply ingrained and extremely difficult to eradicate." ${ }^{24}$ O'Neill (1987: 74) refers to symbolic modes of restitution that respond to a "ruptured moral relationship" between victim and perpetrator. Modes such as apology, forgiveness, and acceptance do "not undo wrongs," she says, "but (at best) they expunge them."

${ }^{25}$ See for example Nickel's point (1974: 148). Goldman, though, wishes to argue that fairness requires that damages be assigned "as specifically as possible" and that individuals must be reimbursed "always in proportion to the actual damages suffered under the unjust policy." Goldman clearly denies the group aspect of such injustices that I am arguing for which does not demand these almost impossible details from victims. His position on the individualist nature of discrimination furthermore states that "discrimination always affects particular individuals, and reparation must be made to specific individuals." This sentence, though true, needs to be qualified as follows: "Discrimination always affects particular individuals insofar as they are members of particular groups, and reparation must be made to specific individuals insofar as they have been direct or indirect victims of the consequences of discrimination based on group characteristics."

${ }^{26}$ Goldman (1977: 235) makes the point that "broad social pressures and stereotypes affect different individuals in different ways." He adds that although all women, for example, might encounter discriminatory attitudes, "it is clear that when these differ in intensity and manifest form, and when some females receive considerable support in their endeavors from others, the long-range psychological effects of such discriminatory effects can also differ."

${ }^{27}$ O'Neill (1987: 75) argues that victims are compensated "if somebody offers them some equivalent for the loss suffered." She adds that compensation "can be done vicariously ... it need not be provided by wrongdoers or by their heirs or representatives."

${ }^{28}$ Wilson (1983: 521) argues for the view that it is "the guilty who... are to "pay back' the innocent... who are to compensate or requite those injured by what they have done, or to make up for it."

${ }^{29}$ Kershnar (1999: 90) argues for the view that all citizens are responsible for compensation, as the government as their agent "omitted to intervene to prevent private persons and state and local officials from committing unjust acts." See also Fishkin's point (1991: 95) that some principle "that holds contemporary institutions responsible for previous acts by those same institutions might be acceptable."

${ }^{30}$ Taylor $(1972-1973$ : 180,181) argues for an obligation to compensate that belongs to every member of society except the victims of injustice. He says that it is "the society in general that, through its established social practice, brought upon itself the obligation."

${ }^{31}$ Goldman's worry (1975: 294) is that "specific individuals who have not caused or received benefit from discrimination will be forced to pay..." Paul (1991) has a similar worry about creating a "new generation of victims" who must "bear the burden of the remedy." There might be individuals who did not cause the injustice, played no part in reinforcing the injustice, and received no benefit in any direct or indirect way from the consequences or effects of the injustice. Would they have reason to complain that small proportions of their taxes are used to compensate victims? The assumption that they would have reason to complain misunderstands how governments differentially distribute tax income to the benefit of interest groups of citizens. If I had no part in any crimes, why should my tax money be used to compensate victims of violent crimes, for example? Alternatively, if I don't travel by road, why should I pay taxes for building and maintaining roads? If the argument is that taxes are 
used for the general interest of society, then compensation for victims of injustice that eliminates bitterness and rebuilds agency would surely also benefit society? Are we victims in any way if our taxes are used for such purposes? Amdur (1979: 233) adds to this view when he says the costs of compensation must be distributed "just the way we distribute the costs of any public good."

${ }^{32}$ Fullinwider (1975: 318) refers to the fact that the benefits of injustice may be received "involuntary and unavoidable." Although whether this is true in all cases might have to be settled empirically, I am strongly convinced that in most cases of injustice protest would be audible and suffering visible enough to argue that the beneficiaries had the moral responsibility of at least recognizing and enquiring about such issues.

${ }^{33}$ Sher (1976-1977: 180) draws a slightly different conclusion about the beneficiaries, saying they "may have benefited from past discrimination; but in a society in which such benefit can hardly be avoided, this is surely not a punishable offence." Sher too easily avoids appealing to the role of their moral agency in such circumstances.

${ }^{34}$ See also some of the distinctions made by O'Neill (1987: 81).

${ }^{35}$ Goldman (1975: 291) defends a principle of compensation that says "injured parties should be compensated, and compensated in kind if possible."

${ }^{36}$ Nagel (1973: 349-350) proposes compensatory measures "in the form of special training programs, or financial support, or day-care centers, or apprenticeships, or tutoring."

${ }^{37}$ See Paul (1991: 101) and note her comment (1991: 103) about the limits of individual compensation when she says that "especially with the passage of much time between the injury and the recompense, restoring the individual to his ex ante position will not fully erase the injurious event."

${ }^{38}$ Goodin (1991: 155) thinks that "little more than token compensation" can be offered in cases where "harms are truly irreparable, and the loss truly irreplaceable." Without denying that some harms are irreparable and some losses irreplaceable, I think compensation in such cases can have more value than being mere tokenism. The value of restoring the equal human value and dignity of victims should especially not be underrated. Creative ways of material compensation could ease a person's life to give compensation more value than mere tokenism.

${ }^{39}$ See Ronald Dworkin's discussion of this issue in his book Sovereign Virtue [2000].

${ }^{40}$ Wade (1978: 464) uses ideas similar to those of average position and relative standing to suggest a criterion when compensatory measures ought to be terminated. He says that point would be reached when victims of injustice [in this case African-Americans] "would have risen to preferred jobs and positions in about the same proportion as other ethnic groups who did not suffer insulting discrimination."

${ }^{41}$ Waldron (1992: 7) says part of the moral significance of the past is "the difference it makes to the present."

${ }^{42}$ This is proposed by Joseph F. Carens (1985: 65) when he says: "I want to argue that ... the best way to institutionalize the ideal of compensatory justice would be to adopt the familiar egalitarian strategy of progressive taxation of high incomes and supplemental transfers to low incomes up to the point where these taxes and transfers interfere too much with market incentives." Onora O'Neill [1987: 87] takes a slightly different approach by arguing for addressing poverty through the restoration of agency rather than "arguing about whether or not we can stretch notions of compensation for violation of rights to cover rectification of selected Third World problems."

${ }^{43}$ Waldron (1992: 27) seems to favor such an approach. He says the following: "If the relief of poverty and the more equal distribution of resources is the aim of a prospective theory of justice, it is likely that the effect of rectifying past wrongs will carry us some distance in this direction. All the same, it is worth stressing that it is the impulse to justice now that should lead the way in this process, not the reparation of something whose wrongness is understood primarily in relation to conditions that no longer obtain."

${ }^{44}$ Waldron (1992: 7) emphasizes that material compensation can have important functions of recognition of injustice and confirming victims' historical identities. He gives an example of compensation in America which was "a clear public recognition that this injustice did happen, that it was the American people and their government that inflicted it, and that these people were among its victims."

${ }^{45}$ Goodin (1991: 143) makes the point that compensatory justice "usually serves to restore some status quo ante ...the notion of some preexisting state that is to be recreated virtually always seems to lie at the core of compensatory justice."

${ }^{46}$ See Rawls [1971]. 